\title{
The importance of clinical management problems in older people with COPD and asthma: do patients and physicians agree?
}

\author{
*Vanessa M McDonald ${ }^{\mathrm{a}, \mathrm{c}}$, Isabel Higgins ${ }^{\mathrm{b}, \mathrm{c}}$, Jodie L Simpson ${ }^{\mathrm{a}, \mathrm{b}}$, Peter G Gibson ${ }^{\mathrm{a}, \mathrm{b}, \mathrm{c}}$ \\ a Department of Respiratory and Sleep Medicine, John Hunter Hospital, New South Wales, Australia \\ b School of Medicine and Public Health, The University of Newcastle, New South Wales, Australia \\ ' School of Nursing and Midwifery, The University of Newcastle, New South Wales, Australia
}

Originally received 7th December 2009; resubmitted 16th March 2010; revised version received 27th July 2010; final revision 28th October 2010; accepted 25th December 2010; online 29th March 2011

\begin{abstract}
Background: COPD and asthma in older people are complex conditions associated with multiple clinical problems. The relative importance of these problems to both patients and physicians and the level of agreement between them is largely unknown.

Methods: Older people with asthma and COPD underwent a multidimensional assessment to characterise the prevalence of clinical problems. Each individual's problems were then summarised and presented separately to the patient and physician to rate problem importance. Problems were scored using a 5-point Likert scale from unimportant to very important.

Results: The highest-rated problems were dyspnoea, activity limitation and airway inflammation, and these areas had good patientphysician concordance. Poor concordance was found for inhaler technique adequacy, airflow obstruction and obesity. Good concordance was found for written action plans, but this was less important to both patients and physicians.

Conclusions: In asthma and COPD, patients and their physicians agree about the importance of managing activity limitation, dyspnoea, and airway inflammation. Other areas of management had little concordance or were viewed as less important. Self-management skills were not rated as important by patients and this may hinder successful management. Eliciting problems and addressing their importance to treatment goals may improve care in COPD and asthma.

(C) 2011 Primary Care Respiratory Society UK. All rights reserved.

VM McDonald et al. Prim Care Resp J 2011; 20(4): 389-395

http://dx.doi.org/10.4104/pcrj.2011.00025
\end{abstract}

Keywords observational, management, COPD, asthma

\section{Introduction}

Obstructive Airways Diseases (OAD) such as chronic obstructive pulmonary disease (COPD) and asthma are common conditions associated with a significant disease burden especially among older populations. COPD is a complex pulmonary and systemic condition associated with multiple clinical problems. ${ }^{1}$ Asthma frequently coexists with COPD and in older people it is also associated with multiple co-morbidities and clinical problems. ${ }^{2}$ These clinical problems have an adverse impact on health status. ${ }^{3,4}$

The management of COPD and asthma is multifaceted and includes not only pharmacotherapy but exercise, smoking cessation, nutrition and self-management education. Facilitating optimal management and person-centred care is challenging in these complex conditions and requires an understanding of both the clinician's and the patient's perspectives of these clinical problems and their treatments. ${ }^{5}$ In other disease areas research has demonstrated that there may be a lack of concordance between the clinician's evaluation of needs and outcomes and the patient's assessments of these needs. ${ }^{6,7}$ This discordance may adversely impact on adherence and ongoing management.

The clinical problems associated with COPD and asthma in older people relate to pathophysiological changes, symptoms,

\footnotetext{
* Corresponding author: Dr Vanessa Marie McDonald, Department of Respiratory and Sleep Medicine, John Hunter Hospital, Locked bag 1, HRMC, Newcastle, New South Wales, 2310, Australia. Tel: +61249213926 Fax: +61249213469 E-mail: Vanessa.McDonald@hnehealth.nsw.gov.au
} 
self-management skills, lifestyle or behavioural choices, and individual problems reported by the patient. ${ }^{2,3}$ These problems may not be elicited by clinicians unless they probe. ${ }^{8}$ Effective management of these clinical issues requires significant behaviour change from the patient to improve outcomes. Successful adherence to these behavioural changes can lead to important improvements in health outcomes. For instance, participation in an exercise programme can improve fitness and reduce symptoms, ${ }^{9}$ smoking cessation decreases the accelerated decline in lung function and improves mortality, ${ }^{10}$ improving nutrition improves outcomes in those who are underweight, ${ }^{11}$ and adhering to pharmacotherapy with appropriate inhaled corticosteroids (ICS) and long-acting bronchodilators improves symptoms, frequency of exacerbations and reduces decline in lung function. ${ }^{12}$ These recommendations form an important part of management in COPD and asthma. However, achieving behaviour change can be difficult, particularly when these changes concern treatments in health care and lifestyle matters. ${ }^{13}$

Bourbeau et al. propose a causal model for behavioural change. This model suggests that in order for an intervention to be successful the patient requires the acquisition of knowledge and skills which leads to improved self-efficacy, followed by behaviour change which results in the positive health effects. ${ }^{14}$ Irwin et al. suggest that patients are more likely to create this behavioural change and implement treatment advice if they perceive these recommendations "as a common sense approach to maintaining health" and if they have a clear appreciation of the nature of their illness and an understanding of treatment risks and benefits. ${ }^{5}$

Behaviour change for healthcare professionals involving a shift from a model of disease-centred care to one of personcentred care may also be necessary to improve patient outcomes. ${ }^{15,16}$ Person-centred care (PCC) is an approach that can improve the patient and clinician relationship ${ }^{15}$ and bring about behavioural change. PCC is a complex and multifaceted concept, and communication is central. This approach aims to bring about concordance between clinicians and patients, ${ }^{17}$ and can improve health outcomes. ${ }^{16}$ PCC requires the clinician to have: an appreciation of the patients' expectations, beliefs and concerns; an understanding of patients' personal circumstances; a willingness and motivation to provide information surrounding the diagnosis, pathology, treatment and prognosis; and knowledge to inform evidence-based treatment decisions..$^{5,18,19}$ Additionally, one of the most basic elements for PCC is agreement between the patient and clinician regarding the patient's needs..$^{5}$ This has been termed "concordance" - the therapeutic relationship between the patient and clinician, and the degree to which the treatment represents a shared decision in which the beliefs and preferences of the patient have been taken into consideration. ${ }^{20}$

In COPD and asthma the relative importance of the multitude of clinical problems to either the patient or their physician is largely unknown; likewise the degree of agreement (concordance) in relation to the relative importance of these clinical problems has not been determined. We hypothesised that there is discordance between the patient and physician in relation to the perceived importance of the clinical problems that exist in COPD and asthma in older people.

The aims of this study, therefore, were to assess patients' and physicians' perceived importance of clinical problems and to describe the level of concordance between patients and physicians in relation to these problems.

\section{Methods}

Older adults with stable OAD (COPD and asthma) were recruited as part of a larger cross sectional study ${ }^{3}$ from the respiratory ambulatory care clinics at the John Hunter Hospital, Newcastle, NSW, Australia. The inclusion criteria for the larger study were people aged 55 years or older, with demonstrated airflow obstruction defined by a prebronchodilator forced expiratory volume in one second $\left(\mathrm{FEV}_{1}\right) /$ forced vital capacity (FVC) ratio ('forced expiratory ratio', FER) $<0.7$ and an FEV $1<80 \%$ of predicted. People were excluded if they had a significant active co-morbidity that would impact on the assessment or study participation (eg. malignancy). If potential recruits had required antibiotics or oral corticosteroids for an acute exacerbation of their airways disease within the previous month, or were experiencing a current acute illness, the study visits were postponed for four weeks until they were stable. All participants had written and verbal English language skills. Ethics approval was obtained from the Hunter New England Human Research Ethics Committee and the University of Newcastle Research Ethics Committee. Participants signed an informed consent.

There were 100 participants who completed the multidimensional assessment ${ }^{3}$ and of these 52 participants (52\%) were invited to (and agreed to) participate in this problem prioritisation study. The remaining 48 had completed the larger study evaluation prior to this sub study commencing and were therefore not invited to participate.

\section{Study design}

Participants attended the research unit for three visits to undergo a multidimensional assessment (MDA) checklist (see Table 1); the assessment included clinical, functional, physiological and biological markers. The results of this study are reported elsewhere. ${ }^{3}$ As part of the MDA, airflow obstruction was assessed using spirometry (KoKo K313100 PDS Instrumentation, Louisville, CO, USA) to measure pre- 
Table 1. Multidimensional assessment used to detect clinical management problems

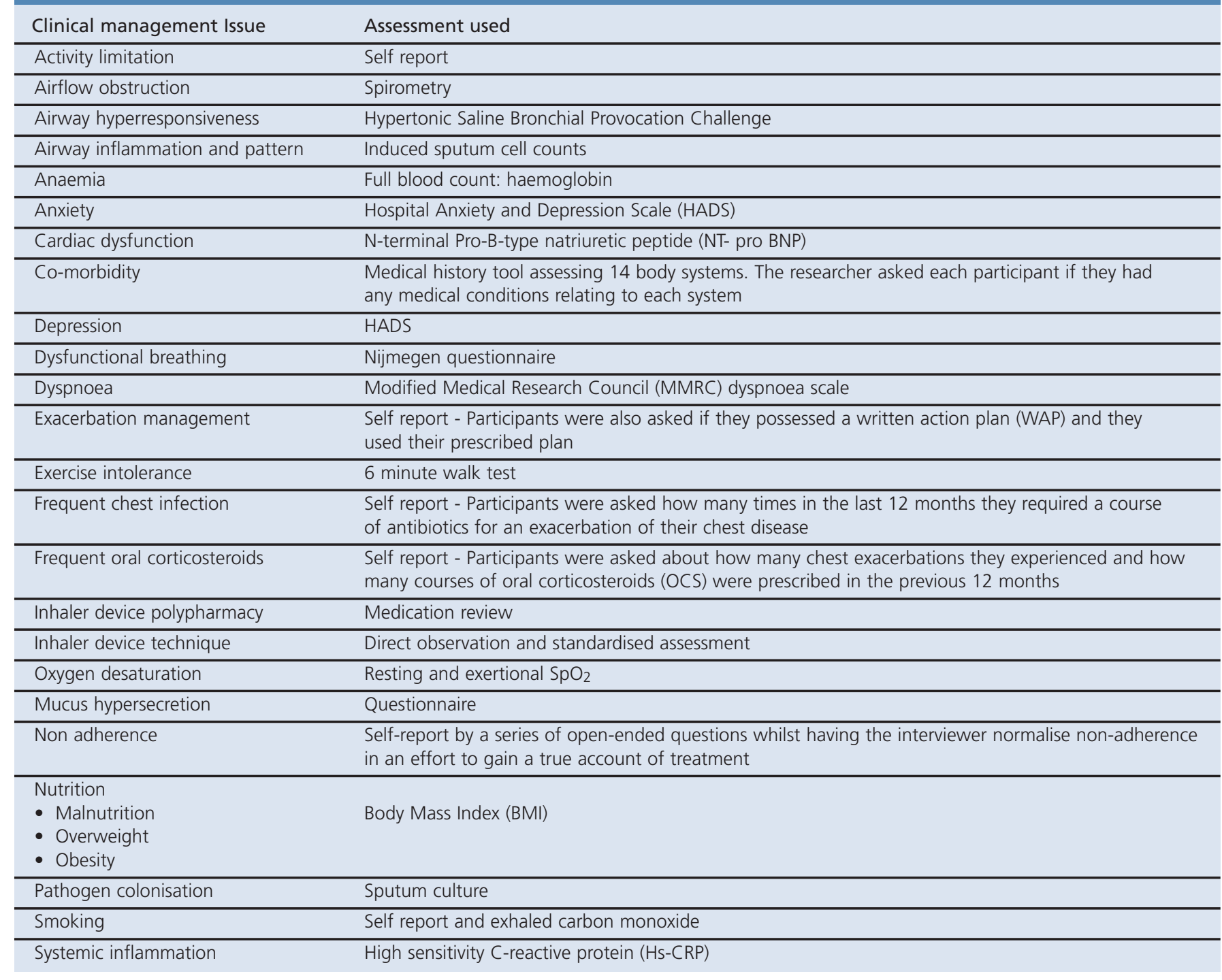

and post-bronchodilator FEV 1, FVC and the FER according to current standards. ${ }^{21}$ Following completion of the MDA, each of the clinical problems that were identified during the assessment were summarised by the study coordinator, a senior respiratory clinician.

Participants were then invited to attend a further visit where the problems identified in the MDA were presented to them. The participant was then asked to rate the importance of each problem. Specifically, they were informed, "The following problems were found to affect your health," and were then asked to, "Please look at the list, and then tell me how important each problem is to the management of your lung condition. Use the scale to rate the importance of each problem. How important is [name each problem here] to your lung health?"

Prior to this visit the study coordinator met with the participant's usual respiratory physician for a case review. The study coordinator presented the doctor with the participant's name, medical history and the individual's problem list. These physicians had referred the participants to the study but were not involved in the study evaluations. Each participant's problem list was scored by the individual's treating physician only.

The physician was informed, "The following problems were found to affect [your patient's name]'s lung health. Please look at the list, and then tell me how important each problem is to the management of your patient's lung condition. Use the scale to rate the importance of each problem. How important is [name each problem here] to their lung health?"

Problems were scored using a 5-point Likert scale, rating problems as unimportant $(=1)$, of little importance $(=2)$, somewhat important (=3), moderately important (=4) and very important $(=5)$. The problems were presented to the physicians using medical terminology, and the participants were presented with a lay-person description and an 
VM McDonald et al.

\begin{tabular}{|c|c|}
\hline Physician Descriptions & Patient Descriptions \\
\hline Smoking & Smoking \\
\hline Anxiety & Higher than usual anxiety score \\
\hline Depression & Higher than usual depression score \\
\hline Mucous hypersecretion & The presence of excessive mucous/phlegm \\
\hline No written action plan & No written plan for when you get flare ups \\
\hline Action plan prescribed but not valid/used & Action Plan prescribed but not valid/used \\
\hline Dysfunctional breathing & Abnormal breathing pattern causing symptoms \\
\hline Hypoxia or hypoxia with exercise & Low oxygen level or Low oxygen level when exercising \\
\hline Airflow obstruction & Airflow Obstructed / blocked \\
\hline Airway hyperresponsiveness & Twitchy airways causing narrowing \\
\hline Obesity & Unhealthy weight range (overweight) \\
\hline Malnutrition & Unhealthy weight range (underweight) \\
\hline Non adherence & Not taking treatment as prescribed \\
\hline Exercise Intolerance & Limitation to exercise \\
\hline Airway inflammation & Swelling or inflammation in the airways \\
\hline Frequent chest infections & Frequent chest infections \\
\hline Frequent exacerbations & Frequent flare up \\
\hline Pathogen colonisation (name) & Disease causing bacteria present in the airways \\
\hline Dyspnoea & Breathlessness \\
\hline Inadequate inhaler technique & Not using inhaler/s correctly \\
\hline
\end{tabular}

explanation was provided by a member of the research team (Table 2). During the scoring the participants and physicians $(n=4)$ were blinded to the others' responses. In order to prevent the physicians routinely scoring the problems similarly, each problem list was presented to the respiratory physicians in random order.

\section{Analysis}

Data were analysed using STATA 9 (Stata Corporation, College Station, TX, USA) software. Normally distributed data are expressed as mean (SD) and non parametric data as median values (interquartile range). Analysis was performed using unpaired $t$ test for mean comparisons. A $p$ value of less than 0.05 was considered statistically significant.

We analysed the problem importance score, problem importance ranking (top 5 important problems), and highly important problems (scored 4 or greater).

We assessed concordance between patient and physician for each of these parameters as the difference in the problem importance rating by patient and physician (Table 4), the top 5 ranked problems by the patient and physician (Table 5), and the percentage of highly important ratings $(>=4)$ for that problem by patient and physician.

\section{Results}

We evaluated 52 participants of whom 21 (40\%) were male. They were aged 55-87 years, with a mean (SD) age of 69.7

\section{Table 3. Participant characteristics}

\begin{tabular}{ll} 
n (participants) & 52 \\
\hline Age in years, mean (SD) & $69.7(7.6)$ \\
Range & $55-87$ \\
\hline Sex M|F & $21 \mid 31$ \\
\hline Pre FEV 1 \% predicted, mean (SD) & $53.7(19.6)$ \\
\hline Post FEV ${ }_{1} \%$ predicted, mean (SD) & $60.6(18)$ \\
\hline Pack years, median (IQR) & $33.7(17-51)$ \\
Current|Ex|Never & $4|28| 20$ \\
\hline Number of clinical problems, mean (SD) & $11(2.7)$ \\
\hline Number of co-morbidities, mean (SD) & $3(1.7)$ \\
Range & $0-8$ \\
\hline *GOLD Stage 1 & 11 \\
Stage 2 & 25 \\
Stage 3 & 13 \\
Stage 4 & 3 \\
\hline St George Respiratory Questionnaire, mean (SD) & $44.8(19.6)$ \\
\hline BMI kg/m², mean (SD) & $30(7)$ \\
\hline \multirow{2}{*}{ *GOLD classifications were calculated using Post FEV 1 \% predicted }
\end{tabular}

(7.6) years and a mean (SD) FEV 1 of $53.7 \%$ predicted (Table 3). There were four respiratory physicians who participated in the scoring; all were male, their mean (SD) age was 59.2 (15.9) years, and their mean (SD) time since graduation was 32.5 (11.9) years. 
Table 4. The most prevalent clinical problems identified by the multidimensional assessment and their respective importance rankings

\begin{tabular}{lllll}
$\begin{array}{l}\text { Problem in order } \\
\text { of prevalence }\end{array}$ & $\mathrm{n}(\%)$ & Patient & Physician & $\mathrm{p}$ value \\
\hline Airflow obstruction & $52(100)$ & $4.4(0.9)$ & $3.6(0.73)$ & 0.0001 \\
\hline Airway inflammation & $38(73)$ & $4.3(1.1)$ & $4.0(0.59)$ & 0.21 \\
\hline $\begin{array}{l}\text { Absence of a Written } \\
\text { Action Plan }\end{array}$ & $35(67)$ & $3.5(1.5)$ & $3.5(0.9)$ & 0.74 \\
\hline Activity limitation & $33(63)$ & $4.6(0.6)$ & $4.2(0.5)$ & 0.007 \\
\hline Dyspnoea & $33(63)$ & $4.7(0.4)$ & $4.2(0.5)$ & 0.001 \\
\hline Atopy & $30(58)$ & $3.5(1.2)$ & $2.7(0.62)$ & 0.02 \\
\hline $\begin{array}{l}\text { Inadequate inhaler } \\
\text { technique }\end{array}$ & $29(56)$ & $3.57(1.5)$ & $4.5(0.5)$ & 0.004 \\
\hline Obesity & $26(50)$ & $4.18(1.1)$ & $3.5(0.76)$ & 0.04 \\
\hline Mucus hypersecretion & $25(48)$ & $3.9(1.0)$ & $3.7(0.69)$ & 0.49 \\
\hline Airway hyperresponsiveness & $22(42)$ & $3.65(1.2)$ & $2.8(0.58)$ & 0.03 \\
\hline Anxiety or depression & $22(42)$ & $4.15(1.3)$ & $4.3(0.5)$ & 0.63 \\
\hline Inhaler device polypharmacy $22(42)$ & $2.9(1.5)$ & $3.5(0.9)$ & 0.10
\end{tabular}

The most common problems of this cohort, identified using the MDA, were airflow obstruction (AFO) in 52 participants $(100 \%)$, airway inflammation $(73 \%)$, the absence of a written action plan in 35 (67\%), and activity limitation and dyspnoea combined in 33 (63\%) (see Table 4).

The highest-rated problems were activity limitation, dyspnoea, and airway inflammation. These were all rated as a score greater than 4 (see Table 5). Concordance of importance rating between the physicians and patients for each problem was calculated by counting all the individual problem scores $\geq 4$ for the physician and patient; the sum is expressed as the percent of scores $\geq 4$. Dyspnoea $(100 \%)$, activity limitation (89\%) and airway inflammation (78\%) all scored highly.

The five highest-rated problems for the participants and physicians are presented in Table 5. Of these, there is further evidence of concordance between the patient and the physician in three of the five most important problems: dyspnoea, activity limitation and airway inflammation.
The remaining problems rated by the participants as the five most important were airflow obstruction and obesity, whereas for the physicians these were inadequate inhaler technique and anxiety/depression (see Table 5). There was discordance in these remaining problems. Whilst inadequate inhaler technique was rated highly important by the physician with a mean (SD) score of $4.5(0.5)$, this was a less important problem to the patients with a score of $3.57(1.5)(p=0.004)$.

Equally, there was discordance between the physician and the patient in areas that the patient rated as highly important. Airflow obstruction was scored as $4.44(0.9)$ by the patient and $3.6(0.73)$ by the physician ( $p=0.0001)$; similarly, obesity was more important to the patient 4.18 (1.1) than the physician 3.5 (0.76) $(\mathrm{p}=0.04)$

There were other clinical problems where concordance was found. However, these problems (related to selfmanagement skills) were rated as less important by both patients and physicians. Concordance between the physicians' and participants' importance rating was seen in the absence of a written action plan, which was scored as 3.5 (1.5) and $3.5(0.9)$ by the participants and physicians respectively $(p=0.74)$. The presence of inhaler device polypharmacy was similarly scored as $2.9(1.5)$ and $3.5(0.9)$ $(p=0.10)$.

\section{Discussion}

This study has demonstrated that in COPD and asthma in older adults there are areas of significant concordance and discordance when it comes to specific management problems. Older patients and their physicians agree about the importance of managing activity limitation, dyspnoea and airway inflammation in asthma and COPD. However, other areas of management rated by either the physician or the patient as important had little concordance. Self-management skills were rated as less important by both the patient and the physician. This, together with the discordance in importance of problems such as obesity, airflow obstruction, inadequate inhaler technique, and anxiety and or depression, may hinder successful management of these problems.

\section{Table 5. Concordance of problems rated as most important by both the patient and the physician}

These are the 5 highest rated problems for the patient and the physician. There was satisfactory concordance between the patient and physician in the problems rated as most important as 3 of the 5 were the same. The highest rated concordant problems were: activity limitation, dyspnoea, and airway inflammation. These were all rated $>4$.

\begin{tabular}{ll|ll}
\hline Patient & Mean (SD) & Physician & Mean (SD) \\
\hline Dyspnoea & $4.7(0.4)$ & Inadequate inhaler technique & $4.5(0.5)$ \\
\hline Activity limitation & $4.6(0.6)$ & Anxiety and depression & $4.3(0.5)$ \\
\hline Airflow obstruction & $4.4(0.9)$ & Activity limitation & $4.2(0.5)$ \\
\hline Airway inflammation & $4.3(1.1)$ & Dyspnoea & $4.2(0.5)$ \\
\hline Obesity & $4.2(1.1)$ & Airway inflammation & $4.3(1.1)$ \\
\hline
\end{tabular}


The problems of activity limitation, dyspnoea and airway inflammation received the highest rating by both the patients and the physicians. These problems have major impacts on outcomes such as health-related quality of life (HRQoL), lung function, ${ }^{22}$ morbidity and prognosis. ${ }^{23,24}$ Dyspnoea and physical limitation are known to be both disabling and important to patients. ${ }^{3,25}$ This study presents reassuring data suggesting that concordance does exist between physicians and patients in these important life-limiting impacts. Further, knowledge that dyspnoea and activity limitation are important to patients, ${ }^{3,25}$ and that the associated poor health outcomes are important factors to clinicians who manage patients, ${ }^{22-24}$ suggests that these results have external validity when examining the importance and concordance of these problems.

Concordance was also seen in some areas of selfmanagement, namely the use of written action plans and the existence of inhaler device polypharmacy. However, whilst patients and physicians had concordant scores, these selfmanagement skills were viewed as less important. Written action plans (WAP) are recommended in international clinical guidelines for asthma and COPD ${ }^{26-28}$ and are well supported by evidence in asthma. ${ }^{29}$ Despite this, uptake of written asthma action plans has been poor. ${ }^{30}$ This may be because physicians don't value the importance of the use of action plans and this has potentially transferred to reflect patient opinions. The data from the present study support this conclusion. Prescription of WAPs requires person-centred communication. ${ }^{31}$ However, physicians report a lack of training in this style of communication and care. ${ }^{5}$ This may contribute to the poor uptake of action plans and the lower priority given to WAPs in this study. This known poor use of WAPs by both patients and physicians again provides some support to the external validity of our results about concordant low priority. One could speculate that improving both physician and patient perception of the importance of WAPs may improve prescription, utilisation and the effect of WAPs in exacerbations of COPD and asthma.

The patients in this study viewed some areas of disease management such as obesity and airflow obstruction as more important than the physicians. In a disease-centred model where the physician's agenda is addressed, ${ }^{32}$ the problems that are important to the patient may not be elicited, acknowledged or addressed. ${ }^{8}$ In a patient-centred model, both the physician's and patient's agendas are addressed and any conflict or discordance between them is dealt with by negotiation. Our data suggest that there is a need to improve patient-centredness by negotiating the problems and treatment to reach better concordance. Identifying problems, eliciting patient agendas, and addressing the importance of problems and treatment goals as seen by both patients and physicians followed by action planning, may improve adherence and care in OAD. Jones et al. ${ }^{33}$ have recently validated a brief simple patient-centred assessment tool to assess the impact of COPD on patients' lives. This may be one way of improving communication and negotiating concordance among patients and clinicians.

There are several limitations to this study. Firstly, with only four respiratory physicians involved, the importance of physician scores for the specific problems cannot be generalised. We suggest that these findings need to be replicated in a wider group of physicians from a variety of clinical settings, particularly in primary and tertiary care.

In a person-centred approach to care the individual's problems are taken into consideration, and the approach we recommend is to establish each individual's problems and then engage in a partnership approach to determine the importance and plan management. Current knowledge relating to dyspnoea, activity and self management adds support to the validity of some of these findings. Conversely, we acknowledge that some of the findings may be centrespecific. For example, in this study, airway inflammation was viewed as highly important by the physicians and the patients. Our centre is one in which markers of airway inflammation are accessible and commonly used, and so the importance of this problem in centres where access to these tests is limited may reveal different results. Nevertheless, we would argue that despite the small number of physicians, this discordance exists as it does in other diseases, ${ }^{6,7}$ and interpretation of the findings based on this limitation should not discourage the need to discuss clinical problems with patients or assess their perception of importance compared to our own.

The use of a 5-point Likert scale for scoring importance had some limitations. It did not allow for a broad range of difference between scores, and this limited our ability to analyse the data using inter-rater statistics.

\section{Conclusions}

In this study, we presented OAD (asthma and COPD) patients and physicians with a list of clinical problems identified during a systematic assessment. Areas of discordance were found and some problems such as self-management skills were given a lower priority by both the patient and the physician. Further investigations are required to examine both the reproducibility of these results in a larger group of physicians and patients, and to establish ways of improving patient/clinician concordance. A model where problems are presented, discussed and agreement regarding importance reached through negotiation and education may improve outcomes for people with COPD and asthma.

\section{Handling editor}

Onno van Schayck 


\section{Statistical review}

Gopal Netuveli

\section{Acknowledgements}

The authors would like to thank Heather Powell and Patrick McElduff for statistical advice.

\section{Conflicts of interest}

VMMCD is supported by the National Health and Medical Research Council (NHMRC) Centre for Respiratory and Sleep Medicine and the Cooperative Research Centre (CRC) for Asthma and Airways. She has participant in educational symposia by AstraZeneca and Novartis. She is on an advisory board for Novartis.

IH has no conflicts to declare.

JLS is supported by the NHMRC Centre for Respiratory and Sleep Medicine. JLS has no conflict of interest to declare.

PGG holds an NHMRC Practitioner Fellowship. He has participated in educational symposia funded by AstraZeneca, Boehringer Ingelheim, GlaxoSmithKline and Novartis, and has participated in studies funded by Pharmaxis and GlaxoSmithKline.

\section{Funding}

This work was financially supported by the National Health and Medical Research Council (NHMRC), the NHMRC Centre for Respiratory and Sleep Medicine, the Cooperative Research Centre (CRC) for Asthma and Airways, the John Hunter Hospital Charitable Trust Research Grants, New South Wales Health Nursing and Midwifery Office and the Hunter Medical Research Institute. The financial sponsors played no role in the design, execution, analysis and interpretation of data or writing of the study.

\section{References}

1 Fabbri LM, Luppi F, Beghé B, et al. Complex chronic comorbidities of COPD. Eur Respir J 2008;31:204-12. http://dx.doi.org/10.1183/09031936.00114307

2 Gibson PG, McDonald VM, Marks GB. Asthma in older adults. Lancet 2010; 376:803-13. http://dx.doi.org/10.1016/S0140-6736(10)61087-2

3 McDonald VM, Simpson JL, Higgins I, Gibson PG. Multidimensional assessment of older people with asthma and COPD: clinical management and health status. Age Ageing 2011;40:42-9. http://dx.doi.org/10.1093/ageing/afq134

4 Antonelli Incalzi R, Pedone C, Pahor M. Multidimensional assessment and treatment of the elderly with COPD. Eur Respir Mon 2009;43:35-55.

5 Irwin RS, Richardson ND. Patient-Focused Care; using the right tools. Chest 2006; 130:73S-82S

6 Laine C, Davidoff F, Lewis CE, et al. Important elements of outpatient care: a comparison of patients' and physicians' opinions. Ann Intern Med 1996; 125:640-5

7 Perrin EC, Lewkowicz C, Young MH. Shared vision: concordance among fathers, mothers, and pediatricians about unmet needs of children with chronic health conditions. Pediatrics 2000;105:277-85.

8 Kravitz RL, Callahan EJ, Paterniti D, et al. Prevalence and sources of patients' unmet expectations for care. Ann Intern Med 1996;125:730-7.

9 Lacasse Y, Goldstein D, Lasserson TJ, et al. Pulmonary rehabilitation for chronic obstructive pulmonary disease. Cochrane Database of Systematic Reviews 2006; Issue 4:Art. No.: CD003793. http://dx.doi.org/003710.001002/ 14651858.CD14003793.pub14651852

10 Godtfredsen NS, Lam TH, Hansel TT, et al. COPD-related morbidity and mortality after smoking cessation: status of the evidence. Eur Respir J 2008; 32:844-53. http://dx.doi.org/10.1183/09031936.00160007

11 Weekes CE, Emery PW, Elia M. Dietary counselling and food fortification in stable COPD: a randomised trial. Thorax 2009;64:326-31.

12 Celli BR, Thomas NE, Anderson JA, et al. Effect of pharmacotherapy on rate of decline of lung function in chronic obstructive pulmonary disease: results from the TORCH study. Am J Respir Crit Care Med 2008;178:322-3. http://dx.doi.org/10.1164/rccm.200712-18690C
13 DiMatteo MR. Variations in patients' adherence to medical recommendations: a quantitative review of 50 years of research. Med Care 2004;42:200-09. http://dx.doi.org/10.1097/01.mlr.0000114908.90348.f9

14 Bourbeau J, Nault D, Dang-Tan T. Self-management and behaviour modification in COPD. Patient Educ Couns 2004;52:271-7. http://dx.doi.org/ 10.1016/S0738-3991(03)00102-2

15 Little $\mathrm{P}$, Everitt $\mathrm{H}$, Williamson I, et al. Observational study of effect of patient centeredness and positive approach on outcomes of general practice consultations. BMJ 2001;323:908-11. http://dx.doi.org/10.1136/bmj.323.7318.908

16 Blasi Di, Harkness E, Ernst E, et al. Influence of context effects on health outcomes: a systematic review. Lancet 2001;357:757-62. http://dx.doi.org/10.1016/S0140-6736(00)04169-6

17 Epstein RM, Franks P, Fiscella K, et al. Measuring patient centered communication in patient-physician consultations: Theoretical and practical issues. Soc Sci Med 2005;61:1516-28. http://dx.doi.org/10.1016/j.socscimed.2005.02.001

18 Stewart M. Towards a global definition of patient centered care. BMJ 2001; 322:444-5. http://dx.doi.org/10.1136/bmj.322.7284.444

19 Bauman $A E$, Fardy HJ, Harris PG. Getting it right: why bother with patientcentered care? Med J Aust 2003;179:253-6.

20 Horne R. Compliance, Adherence, and Concordance - Implications for Asthma Treatment. Chest 2006;130:65S-72S. http://dx.doi.org/10.1378/chest.130.1_suppl.65S

21 Miller MR, Hankinson J, Brusasco V, et al. Standardisation of spirometry. Eur Respir J 2005;26:319-38. http://dx.doi.org/10.1183/09031936.05.00034805

22 Garcia-Aymerich J, Lange $\mathrm{P}$, Benet $\mathrm{M}$, et al. Regular physical activity modifies smoking-related lung function decline and reduces risk of chronic obstructive pulmonary disease: a population-based cohort study. Am J Respir Crit Care Med 2007;175:458-63. http://dx.doi.org/10.1164/rccm.200607-8960C

23 Tessier JF, Nejjari C, Letenneur L, et al. Dyspnea and 8-year mortality among elderley men and women: the PAQUID cohort study. Eur J Epidemiol 2001; 17:223-29. http://dx.doi.org/10.1023/A:1017977715073

24 Celli BR, Cote CG, Marin JM, et al. The Body-Mass Index, Airflow Obstruction, Dyspnea, and Exercise Capacity Index in Chronic Obstructive Pulmonary Disease. $N$ Engl J Med 2004;350:1005-12. http://dx.doi.org/10.1056/NEJMoa021322

25 Williams V, Bruton A, Ellis-Hill C, et al. What really matters to patients living with chronic obstructive pulmonary disease? An exploratory study. Chron Respir Dis 2007;4:77-85. http://dx.doi.org/10.1177/1479972307078482

26 GINA. Global Strategy for asthma Management and Prevention. Global Strategy for Asthma Management and Prevention: NHLBIMHO Workshop Report, 2006

27 Pauwels RA, Buist AS, Calverley PM, et al. NHLBI/WHO Global initiative for chronic obstructive lung disease (GOLD) Workshop summary. Am J Respir Crit Care Med 2001;163:1256-76.

28 McKenzie D, Frith P, Burdon J, et al. The COPDX plan: Australia and New Zealand guidelines for the management of Chronic Obstructive Pulmonary Disease. Med J Aust 2003;178:S1-S40.

29 Gibson PG, Powell H, Coughlin J, et al. Self-management education and regular practitioner review for adults with asthma. Cochrane Database of Systematic Reviews 2003

30 Wilson DH, Adams RJ, Appleton SL, et al. Prevalence of asthma and asthma action plans in South Australia: population surveys from 1990 to 2001. Med J Aust 2003;178:483-5.

31 McDonald VM, Gibson PG. Asthma self-management education. Chron Respir Dis 2006;3:29-37. http://dx.doi.org/10.1191/1479972306cd090ra

32 Levenstein JH, McCracken EC, McWhinney IR, et al. The patient-centred clinical method. 1. A model for the doctor-patient interaction in family medicine. Fam Pract 1986;3:24-30. http://dx.doi.org/10.1093/fampra/3.1.24

33 Jones PW, Harding G, Berry P, et al. Development and first validation of the COPD Assessment Test. Eur Respir J 2009;34:648-54. http://dx.doi.org/ 10.1183/09031936.00102509 